\title{
LA HISTORIOGRAFÍA PORTUGUESA DE LA DECADENCIA EN EL SIGLO XIX Y EL SISTEMA DE CORTE: RELATOS DESDE EL LIBERALISMO REPUBLICANO Y EL SOCIALISMO
}

\author{
Manuel López Forjas \\ (Universidad Autónoma de Madrid) \\ manuel.lopezf@uam.es
}

\section{RESUMEN}

En este artículo se expone la interpretación que hicieron los autores de la generación de 1870 en Portugal acerca del sistema cortesano y de la decadencia de las monarquías de España y de Portugal durante la Edad Moderna. En primer lugar, se contextualizan brevemente las problemáticas políticas e ideológicas que historiadores de la generación anterior como Herculano, Vasconcelos y Garrett, se plantearon en torno a su propia época. En segundo lugar, se propone una revisión y un análisis de las ideas que Antero de Quental y Oliveira Martins plasmaron en torno a la corte y a la decadencia de España y de Portugal. Finalmente, se concluye con una muy breve síntesis sobre los avances de la historiografía acerca de la corte y del tema de la decadencia; con el fin de situar de una manera precisa el desarrollo científico que rodeó a los filósofos de $1870 \mathrm{y}$, de esta forma, difundir su pensamiento para los lectores de lengua española.

PALABRAS CLAVE: Corte; decadencia; Almeida Garrett; Antero de Quental; Oliveira Martins.

\section{THE NINETEENTH CENTURY PORTUGUESE HISTORIOGRAPHY ABOUT THE DECADENCE AND THE COURT STUDIES: REFLECTIONS FROM LIBERAL REPUBLICANISM AND SOCIALISM}

\begin{abstract}
In this article, I present the interpretation that the authors of the generation of 1870 in Portugal wrote about the court system and the decadence of the monarchies of Spain and Portugal during the Early Modern period. Firstly, I offer a revision of the context and the political and ideological problems that historians of the previous generation, such as Herculano, Vasconcelos and Almeida Garrett thought about their own era. Secondly, I propose a description and an analysis of the ideas that Antero de Quental and Oliveira Martins have shaped around the court and the decadence of Spain and Portugal. Finally, this work concludes with a brief summary of the recent historiographical studies that are focused on the court and the theme of decadence. This method has the purpose to be precise at understanding the scientific development
\end{abstract}


that surrounded the philosophers of 1870. In this way, this project can present their original ideas to the Spanish-speaking readers.

KEY WORDS: Court; decadence Almeida Garrett; Antero de Quental; Oliveira Martins.

\section{HISTORIA Y CONSTRUCCIÓN DE LA NACIÓN}

Desde el primer cuarto del siglo XIX, la política portuguesa se enfrentó con la necesidad y la tarea de construir una nación que debía ser moderna y avanzada con respecto al ideal de progreso de las potencias de Europa, -sobre todo una vez que perdió Brasil en 1822-. Este fenómeno se desarrolló, según lo explicó António Manuel Hespanha, gracias al contubernio entre los políticos y los autores quienes se habían constituido como los «primeros historiadores» en torno a la superación del pasado y del llamado «Antiguo Régimen»; lo cual, conllevó a explicar el tema de la decadencia de la nación a partir de la crítica de la centralización monárquica desde los siglos anteriores -crítica que se efectuaba desde las distintas y opuestas ideologías políticas de la época: desde el tradicionalismo hasta el jacobinismo- ${ }^{1}$.

El deseo de europeización comenzó a arraigarse con firmeza entre los autores de la época y se acentuaba frente a un sentimiento de desvaloración con respecto a los grandes países vecinos. Ante el desarraigo simbólico y político que sentían hacia el desarrollo y la modernidad europeos, se propusieron crear una historia nacional que le diera un sentido a lo que vendría a formar parte de su propia «tradición» y de su propia «memoria» ${ }^{2}$. Por lo tanto, se trataba de un proyecto donde confluían posturas políticas opuestas y hasta contradictorias entre sí, pero que respondía al nuevo espíritu de la época, donde el papel de Portugal en la historia estuviese suficientemente justificado.

Surgieron así relatos de construcción de la historia del siglo XIX, en los que predominaba un enfoque de la evolución de la nación a través de las épocas y de los siglos desde un punto de vista esencialista. Las diferencias se acentuaban, sobre todo, cuando querían colocar los puntos de inflexión del avance natural del «pueblo» o de la «nación» portuguesa y, aun en estos aspectos, había diferencias entre los autores que seguían más o menos la misma corriente ideológica. Los matices se correspondían con las circunstancias particulares del autor; tales como su formación intelectual y sus vivencias dentro y fuera de su lugar de origen.

\footnotetext{
${ }^{1}$ António Manuel Hespanha, Visperas del Leviatán (Madrid: Taurus, 1989), 33.

2 Sérgio Campos Matos, Historiografía e Memória (Lisboa: Colibri, 1998), 19.
} 


\subsection{La historia y el Liberalismo en portugal: antecedentes}

Uno de los mayores y principales historiadores novecentistas portugueses fue Alexandre Herculano (1810-1877), quien originalmente se dedicó a la Historia Antigua y Medieval pero que también se preocupó por el tema de la decadencia en la Edad Moderna y en su propia contemporaneidad. Herculano se volvió un autor de referencia para los autores setentistas, es decir, los que analizaron con mayor atención el tema de la decadencia y donde se encuentran nombres como Antero de Quental y Joaquim Oliveira Martins; con la peculiaridad que en el relato de la história patria portuguesa, Herculano trazaba un camino propio e independiente de España y ponía el eje de su análisis en el desarrollo de la Casa Real hasta su evolución en la nueva nación portuguesa.

Un caso distinto es el de António Teixeira de Vasconcelos (1816-1878), quien vivió en París y ahí publicó en 1859 su libro Le Portugal et la Maison de Bragançe. El autor quería combatir las visiones negativas que los ilustrados franceses habían mostrado sobre su país y, al mismo tiempo, dar una buena imagen de las cualidades del pueblo portugués. Seguía, como Herculano, una perspectiva evolucionista a partir de la propia Casa Real hasta desembocar en la nación moderna; pero no tenía problema en mostrar las relaciones entre Portugal y España, esperando que «en el futuro, manteniendo cada una su autonomía, las dos nacionalidades llegasen a ser constituidas por un solo pueblo» ${ }^{3}$.

Si se considera que el régimen liberal se instaló definitivamente en Portugal en 1834, se puede afirmar que los procesos de recrear esas historias patrias seguían -cada uno desde su postura ideológica- el propósito de contribuir a la integración nacional a través de la cultura histórica que estaban fomentando: lo que constituyó un «explícito programa de nacionalismo culturalı ${ }^{4}$.

El nuevo régimen liberal tenía que explicar la historia «gloriosa» de Portugal: invadido por las huestes napoleónicas a principios de siglo, que se había enfrentado a una «revolución liberal» (paralelamente al Trienio en España) y que sufrió intestinas guerras civiles entre los partidarios de la monarquía absoluta y los que abogaban por un gobierno constitucional ${ }^{5}$. Además, se debe considerar que entre 1834 y 1851, pese al triunfo constitucionalista, tuvieron que cambiar de Carta Magna tres veces y en todas se realizó por la vía violenta ${ }^{6}$.

Económicamente, tenían que salir de una crisis del comercio exterior que estaba en ruinas, la cual se acentuó más por la pérdida del monopolio del mercado

\footnotetext{
${ }^{3}$ Ibídem, 99. Esta visión desembocaría en los múltiples y también contradictorios proyectos de lo que se conoce como iberismo. Para una revisión actual del tema, puede consultarse al propio Sérgio Campos Matos, Iberismos: nação e transnação, Portugal e Espanha c. 1807-1931 (Coimbra: Imprensa da Universidade de Coimbra, 2017).

${ }^{4}$ Campos Matos, Historiografía e Memória, 475, 494.

${ }^{5}$ Douglas Wheeler, Republican Portugal. A Political History 1910-1926 (Wisconsin: University of Wisconsin Press, 1978), 7.

${ }^{6}$ Maria de Fátima Bonifácio, História e Ideologia. Uma polemica Novecentista (Lisboa: Editorial Presencia, 2017), 24
} 
brasileño que pasó a manos de los británicos. Esta intervención hizo que la economía portuguesa se volviera mucho más dependiente de aquel imperio. La solución que los políticos encontraron para no perder su identidad y garantizar el comercio fue el proteccionismo económico; medida que, a pesar de su intención de defensa nacional, tuvo que ceder y dar concesiones frente las ambiciones mercantiles británicas, las cuales regían la economía nacional según la intención explícita de George Canning cuando afirmaba que «Portugal has been and always must be English» ${ }^{7}$. Esto sucedió porque, aunque la facción cartista o constitucionalista se declaró a favor del librecambio de acuerdo a su ideología, tuvo que volverse proteccionista por «pragmatismo político» ${ }^{8}$. Tales factores condicionaron, sin duda, los primeros relatos historiográficos -en tanto su pretensión de cientificidad- que ofrecieron una visión panorámica del pasado portugués con el fin de reinterpretar su presente y modernizarlo.

\subsection{Un liberal ¿conservador?: Garrett y las bases de una historiografía republicana}

Después de la convulsa primera mitad del siglo XIX, llena de crisis financieras y prácticamente «al borde de la bancarrota» como lo señala Pedro Calafate, se generó lo que considera como la ocasión en la historia en la cual se reflexionó más sobre el papel de Portugal y sobre «su destino en la senda del progreso y en el marco de la decadencia de los pueblos» ${ }^{9}$. Al mismo tiempo que comienza a incorporarse la categoría de «soberanía populan» en el discurso ideológico de los liberales y antimonárquicos del siglo XIX -ya fueran republicanos o federalistas-; estos autores introdujeron también los conocimientos que iban adquiriendo de las incipientes ciencias sociales; como la antropología y la sociología ${ }^{10}$.

\footnotetext{
${ }^{7}$ Esta frase, efectivamente, la escribió de forma textual el Ministro británico de Asuntos Exteriores, George Canning, en una carta al biógrafo Augustus Granville, fechada el 21 de enero de 1825 desde la Foreign Office. En el contexto inmediatamente posterior a las Guerras Napoleónicas, Canning enfatizó esa frase frente a la ineptitud de Jules de Polignac, líder del partido ultrarrealista de Francia. Calificó su actitud de dicha manera por externar su envidia sobre el dominio de Portugal que los ingleses tenían. Canning, en su confidencia a Granville, insistió en la importancia del dominio británico sobre el país luso para mantener un equilibrio en Europa; pues consideraba que una vez que Portugal perteneciera a Francia, pronto sería anexada a la monarquía española. Augustus Granville Stapleton, George Canning and his times (London: John W. Parker and Son, West Strand, 1859) 509. Esta frase sería recuperada y puesta en circulación ya en el siglo XX por Elie Halévy, A History of English People in the Nineteenth Century. Volume II. The liberal awakening (1825-1830), (London: Barnes \& Noble, 1961), 245.

${ }^{8}$ Bonifácio, História e Ideologia, 356, 366.

9 Pedro Calafate. "Introdução", en Portugal como problema. Século XIX. A decadência. Volume III, ed. Pedro Calafate (Lisboa: Fundaçao Luso-Americana y Público, 2006), 14-15.

${ }^{10}$ Es interesante que, tanto en España como en Portugal, tuvieron mucho eco en los círculos republicanos y liberales las teorías en torno a la psicología de los pueblos y su decadencia, varias décadas antes que se publicaran los ensayos clásicos al respecto en Europa: desde un punto de vista más científico se debe mencionar los estudios de Wundt sobre la psicología de los pueblos (Völlkerpsychologie) a principios del siglo XX; mientras que desde un enfoque más sociológico el de Gustave Le Bon y su estudio sobre las muchedumbres de 1895.
} 
Uno de los principales autores que participaron en estos debates fue el escritor romántico de Oporto, Almeida Garrett (1799-1854). En un inicio, mostró una ideología liberal-igualitaria y a favor de la soberanía popular desde el grupo cartista (más adepto a una monarquía parlamentaria de ideología centralista). Compañero y lector del historiador Alexandre Herculano, Garrett escribió una obra sobre Portugal en la balanz̧a de Europa y de la civilización moderna (1830); donde se dirigía a la nación portuguesa de un modo análogo a como Demóstenes lo hizo con los atenienses en la Grecia clásica: a través de un inspirado discurso republicano que fomentaba el patriotismo y la libertad de los ciudadanos de la pólis.

Como se observa desde el mismo título, su diagnóstico no se limitaba solamente al caso portugués, sino que también y, sobre todo, se dirigía a los pueblos europeos en general. En su análisis partía justamente de la Edad Moderna y se lamentaba que las libertades de las «naciones europeas» se vieron ofuscadas en el siglo XVI por la «tiranía» y el «despotismo» que Carlos V de Alemania y I de España estaba implantando, no solo en el viejo continente, sino también en el Nuevo Mundo. Incluso, llegó a hablar de una tiranía que tenía a su servicio al cristianismo, traicionando la raíz de éste que, según él, se basaba en lo contrario: en la defensa de los pueblos frente a los tiranos ${ }^{11}$.

Garrett, como se aprecia, no oponía España frente a Portugal, sino que los colocaba en una misma situación de lucha contra el «liberticida» Carlos V. Buscaba ser un ejemplo para las otras «naciones» europeas y mostrar que era posible vencer al Emperador en nombre de la civilización, castigando así a quien se había convertido en un «apóstata» de las libertades que prometió y que solo oprimió ${ }^{12}$. Empero, la consecuencia negativa de esta dominación en Portugal fue que la Casa de Braganza transmitió al Nuevo Mundo la imagen de un monarca y una corte llena de espectáculos y lujos, de una aristocracia que vivía en los palacios y que rendían pleitesías a los gobernadores y obispos; mientras que los súbditos se regían por una suerte de «ley común de trabajo» ${ }^{13}$.

Garrett, ideológicamente, no condenaba a la monarquía como sistema de gobierno; sino a su visión degenerada: que en la teoría política es la tiranía. De hecho, él creía que la monarquía portuguesa se basaba en un origen democrático, el cual fue el principio que según él se rescató tras las Cortes de 1640 y la separación de las Coronas de España y de Portugal. La monarquía, como forma de gobierno, la vinculaba a una especie de libertad parlamentaria o constitucional que se vio aniquilada con el retorno de Fernando VII y su desprecio a los principios de la Constitución de Cádiz, volviendo así a los «absurdos, y a las incoherentes y funestas instituciones de la monarquía teocrática de los Felipes» ${ }^{14}$.

Portugal estaba al tanto de su país vecino y del nuevo orden que Cádiz había prometido, pero al ver la opresión que se restituía en España, también se encontraba

\footnotetext{
${ }^{11}$ Almeida Garrett, Portugal na balança da Europa; do que tem sido e do que ora lhe convém ser na nova ordem de coisas do mundo civilizado (Londres: S.W. Sustenance, 1830), 16, 25.

12 Ibídem, 37.

13 Ibídem, 50.

14 Ibídem, 58.
} 
limitada por el fantasma de su independencia creado por las potencias europeas, cuando en verdad éstas no la dejaban respirar. Garrett consideraba que el espíritu nacional de su pueblo, basado en la libertad, fue velado por una mala administración y, sobre todo, por una falta de respeto de las naciones europeas a sus bases; lo cual lo debilitó al punto que quedó «más pobre y más flaco que cualquier otra potencia» ${ }^{15}$.

Si la Europa de su tiempo, es decir, de comienzos del siglo XIX estaba constituida por monarquías modernas, Portugal participaba del mismo espíritu y lo hacía desde sus propias bases, agregando además un principio «aristocrático», por una parte, -debido a sus costumbres desde la Reconquista- y «democrático», por la otra ya que el comercio y las riquezas que alcanzó, así como el nivel ilustrado y cultural, permitieron el surgimiento de una «clase media» ${ }^{16}$.

Garrett se identificaba con la soberanía popular proclamada por las supuestas Cortes de Lamego (1139-1143) que Herculano ya había estudiado y datado más bien en el siglo XVII y que serviría de estandarte del triunfo liberal de 1834; pues ahí estaban representados el Rey, la aristocracia y los procuradores de los concejos «representantes de la democracia portuguesa»-. Para él, ese era el espíritu que había guiado a Portugal en la historia y del cual se enorgullecía, sin importarle el carácter apócrifo o no de las Cortes de Lamego ${ }^{17}$.

Su posición política fue mayormente recuperada por la generación liberal posterior que combatió ideológicamente a los partidarios de la Regeneração (1851-1890) -gobierno que alegaba haber puesto un equilibrio entre los progresistas radicales y los conservadores constitucionalistas del gobierno anterior, que era dirigido por Costa Cabral-. Garrett en realidad, a pesar de haber ocupado cargos oficiales durante la Regeneração, tampoco consideraba que este gobierno cumpliera cabalmente su ideal constitucional cristiano. Aunque se puede afirmar que esta última etapa, sumada a su participación con el cartismo en la década de 1830, lo asocia al conservadurismo ${ }^{18}$; también se debe decir que las ideas liberales de Garrett - en tanto europeístas y a favor de la soberanía popular- pervivieron en el republicanismo y en el socialismo portugueses de la segunda mitad del siglo XIX.

\footnotetext{
15 Ibídem, 283.

${ }^{16}$ Ibídem, 293-297.

${ }^{17}$ Sobre esta construcción, puede verse el texto de Sérgio Campos Matos, "Nación. Portugal", en Diccionario político y social del mundo iberoamericano. La era de las revoluciones, 1750-1850 [Iberconceptos-I], dir. Javier Fernández Sebastián (Madrid: Fundación Carolina/Sociedad Estatal de Conmemoraciones Culturales/Centro de Estudios Políticos y Constitucionales, 2009), 953-966. Esta vitalidad proporcionada a un mito medieval tiene un gran paralelismo con el episodio de la Jura de Santa Gadea del Cantar del Mío Cid y el uso político que Joaquín Costa hizo de él para justificar la idealización de una tradición republicana en España, sobre todo para la época del Regeneracionismo.

${ }^{18}$ Maria de Fátima Bonifácio, Fora da circunstância. Ensaios polémicos sobre grandes questões da actualidade (Alfragide: D. Quixote, 2019), 109-125.
} 


\section{ANTERO DE QUENTAL: SU VISIÓN NEGATIVA DE LA CORTE}

Uno de los filósofos más importantes del setentismo fue precisamente Antero de Quental (1842-1891), un crítico rotundo de la que llamaba la «monarquía absoluta» de Carlos V, pues concebía que en ese periodo se atentó contra las libertades y fueros municipales que paradójicamente, como señala Calafate, pasaron a España a manos de un rey que ni siquiera era español ${ }^{19}$.

Ideológicamente, después de seguir el romanticismo de Schiller, Antero transitó al positivismo; pues consideraba que las ciencias podían resolver los problemas de la humanidad y, por ende, el socialismo permitiría resolver el desorden moral del mundo desde la conciencia y con un programa educativo y de renovación social a través de una transformación lenta, pero racional. Todavía en 1860, mantendría una visión positiva del cristianismo como una idea sublime e incluso aplaudió el papel civilizador de los pueblos europeos y su papel evangélico; al considerar que sería sustituido finalmente por una religión universal de la humanidad ${ }^{20}$.

A nivel político, Antero se identificaba con el republicanismo y se podría decir también, con un sobrio anarquismo, en la medida en que introdujo el pensamiento de Proudhon a Portugal. Predominantemente, escribía en contra de los historiadores y políticos del régimen de la Regeneração (1851-1890), el gobierno conservador que defendía una retórica a favor de un nacionalismo luso tradicionalista y católico, teniendo como uno de sus máximos representantes al político Fontes Pereira de Melo ${ }^{21}$, -quien inspiraría incluso una corriente ideológica en el periodo posterior a la Regeneración que se conoció precisamente como fontismo-.

Antero tenía muy claro que debía llevar la modernidad a la sociedad portuguesa, para superar el despotismo y el catolicismo promovido por la Regeneración, a través de una revolución pacífica ${ }^{22}$. Ya proponía entonces una distinción entre catolicismo y cristianismo, que ocupará sobre todo en su crítica al Concilio de Trento. Pertenecía al círculo literario que se llamó O Cenáculo, donde participaban también Oliveira Martins y el gran novelista y poeta Eça de Queirós; con quienes organizó un ciclo de conferencias en el Casino de Lisboa en 1871. Este ciclo quedó inconcluso debido a que el gobierno de la Regeneração lo canceló por los contenidos aparentemente subversivos de las conferencias que se estaban impartiendo. En la queja que le presentó al Consejo de Ministros, Antero agregó que «cuando la península deje de ser católica, volverá a ser cristiana» ${ }^{23}$.

19 Pedro Calafate, “A reflexão sobre Portugal na viragem do século", en Filosofía y Literatura en la peninsula ibérica. Respuestas a la crisis finisecular. I Jornadas Luso-Espanbolas de Filosofía, Lisboa, 2009, ed. Pedro Calafate, José Luis Mora García y Xavier Agenjo Bullón (Madrid: Fundación Ignacio Larramendi, 2012), 28.

${ }^{20}$ Leonel Ribeiro dos Santos, Antero de Quental. Uma visão moral do mundo (Lisboa: Imprensa Nacional Casa da Moeda, 2002), 36, 87-89, 131-132.

${ }^{21}$ César Rina, "Decadencia, regeneración y revolución. La historia peninsular según Antero de Quental”, en Causas de la decadencia de los pueblos peninsulares, Antero de Quental,. Traducción y prólogo de César Rina Simón (Madrid: Marcial Pons, 2017), 28.

22 Ibídem, 32.

23 Ibídem, 33. 
Precisamente, en su conferencia del 17 de mayo de 1817 en el Casino Lisbonense, donde habló sobre las Causas de la decadencia de los pueblos peninsulares, se posicionó críticamente frente a la historiografía del fontismo que ponía en relación la grandeza de la nación con el Concilio de Trento, la colonización en ultramar y el absolutismo. Por esta razón, señalará estos elementos como las principales causas de la decadencia en España y en Portugal. Más allá de las visiones liberales o tradicionalistas de la historiografía decimonónica, intentaba superar la decadencia a partir de una toma de conciencia. Sin embargo, su discurso fue velado e incluso malinterpretado ventajosamente por la dictadura de Oliveira Salazar en el siglo XX, usando al propio Antero como símbolo de su autoritarismo ${ }^{24}$.

\subsection{El surgimiento del problema en los pueblos de España y en Portugal}

Como se había dicho anteriormente, Antero de Quental tenía una visión positiva de las libertades municipales de la Edad Media, afirmando que Portugal había adquirido un papel predominante en la Europa del Renacimiento. El inicio del problema lo databa a principios del siglo XVII, como consecuencia de la «monarquía anómala, inconsistente y antinatural de Felipe $\mathrm{II} »^{25}$. La decadencia afectaría a todos los ámbitos de la vida portuguesa y atentaría sobre todo al «espíritu del pueblo portugués», caracterizado por una suerte de constante independencia local.

Dado que Felipe fue II de Castilla y I de Portugal, las consecuencias negativas las encontraba en ambos territorios a finales del siglo XVII. Esto lo prolongaba, en una perspectiva de larga duración, hasta el siglo XVIII, donde criticaba a Felipe V por establecer una política «antinacional» que le quitaría todo su valor a la monarquía, desarticulándola por completo; mientras que Portugal pasaría por una situación semejante:

¡Y ese rey extranjero cuesta a España la pérdida de Nápoles, Sicilia, del Milanesado, de los Países Bajos! En Portugal, es la influencia inglesa que, por medio de astutos tratados, hace de nosotros una especie de colonia británica. Al mismo tiempo, nuestras propias colonias se nos escapan gradualmente de las manos: las Molucas pasan a ser holandesas; en la India luchan por nuestros despojos holandeses, ingleses y franceses: en China y Japón desaparece la influencia del nombre portugués. Portugueses y españoles, vamos de siglo en siglo menguando en extensión e importancia, hasta no ser más que dos sombras, jdos espectros de naciones en medio de los pueblos que nos rodean...! $[\ldots . .]^{26}$

De esta forma, opuso los fueros y libertades municipales que se perdieron frente al nuevo sistema que encontraba inútil, basado en la centralización y en un absolutismo total. Efectuó una crítica total a la idea de pater familias que sustentaba el sistema cortesano, pues reclamaba que la realeza «cree ingenuamente que los pueblos

\footnotetext{
${ }^{24}$ Ibídem, 36-41.

25 Antero de Quental, Causas de la decadencia, 59.

${ }^{26}$ Ibídem, 60.
} 
no son más que el patrimonio providencial de los reyes ¡Lo peor es que los pueblos se acostumbran a creerlo también! $»^{27}$. Para Antero, siguiendo los modelos de la psicología de los pueblos (que les atribuye una conciencia social y una personalidad colectiva), la noción providencialista del patrimonialismo era insostenible.

Tampoco podía aceptar que, frente a los grandes científicos y filósofos de Alemania (Leibnitz), Francia (Descartes), Inglaterra (Newton) e incluso Italia (Vico), no figurara a ese nivel un nombre español o portugués: «La Europa culta se engrandeció, se dignificó, prosperó sobre todo por la ciencia. Fue sobre todo por la falta de ciencia que nosotros entramos en decadencia, que nos degradamos, que nos anulamos. El alma moderna murió por completo dentro de nosotros» ${ }^{28}$.

Además, introdujo a su crítica el tópico de la corrupción de las costumbres y la depravación de las cortes reales tanto en los reinados de la monarquía hispana como de la portuguesa. No dejó fuera de al brazo eclesiástico, recordando las historias picarescas de los frailes recogidas en el Decamerón de Bocaccio y aplicándolas a los siglos XVII y XVIII; además de mencionar a la Inquisición como un instrumento mediante el cual ejercían su carácter «sanguinario» ${ }^{29}$. Por una parte, seguía el esquema crítico de los arbitristas y proyectistas, pero a diferencia de dichos autores -la mayoría fueron letrados o servidores de la monarquía-, él acentuó el papel de la Inquisición como un elemento negativo; considerándolo únicamente como un tema religioso, sin tener en cuenta su conformación en tanto Consejo Real.

\subsection{Análisis de las tres causas de la decadencia}

Si bien estaba discutiendo con los historiadores nacionalistas que exaltaban elementos históricos como 1) el Concilio de Trento, 2) el poder real y 3) las posesiones ultramarinas; Antero intentaba replantear esos tópicos, primero desde una perspectiva crítica, para luego ser capaz de proponer una superación que colocaba allende el campo de la historiografía: apuntando a la resolución de los problemas que encontraba en su propia época. Su descripción de los elementos que, a su juicio, provocaron la decadencia de los pueblos ibéricos terminó por inspirar a los historiadores posteriores que retomarían o matizarían sus argumentos principales.

A cada una de las tres causas le atribuyó un carácter específico, mostrando que la decadencia se trataba en todas sus dimensiones principales; aunque cada elemento se interrelacionaba en una dimensión espiritual. El catolicismo - no el cristianismo- del

${ }^{27}$ Ibídem, 62. Se debe tener en cuenta que, en el sistema cortesano, el orden natural se justificaba mediante la idea de sociabilidad aristotélica, mediante el cual la familia era la base de un orden jerárquico, con el padre a la cabeza; lo cual se volvió el modelo social de la Edad moderna. José Martínez Millán y Carlos Javier de Carlos Morales, Religión, política y tolerancia en la Europa Moderna (Madrid: Polifemo, 2009), 296.

28 Antero de Quental, Causas de la decadencia, 64. La crítica de Antero en este punto va muy de la mano con la polémica de la ciencia en España durante el siglo durante el siglo XIX, la cual ha sido bien reconstruida por Ramón E. Mandado Gutiérrez y Gerardo Bolado Ochoa (dirs.), La Ciencia Española. Estudios (Santander: Real Sociedad Menéndez Pelayo/Ediciones de la Universidad de Cantabria, 2011).

${ }^{29}$ Antero de Quental, Causas de la decadencia, 65. 
Concilio de Trento representaría el aspecto moral; el absolutismo y la desaparición de los fueros locales sería el carácter político y las conquistas ultramarinas corresponderían a la dimensión económica ${ }^{30}$.

El esquema que usaba, característico de su espíritu decimonónico, intercalaba las categorías de conquista y de colonización. La diferencia fundamental entre el progreso de las «naciones» europeas y el decaimiento de las peninsulares es que las primeras, al estar basadas en dicha tolerancia, crearon iglesias «nacionales» independientes que no imponían sus dogmas y que, incluso, las de confesión católica, se abrieron a una conciliación con los protestantes.

Así, mientras las otras naciones crecían, nosotros decaíamos. Crecían ellas por las virtudes modernas; nosotros decaíamos por los vicios antiguos, concentrados, llevados al máximo grado de desarrollo y aplicación. Decaíamos por la industria, por la política. Decaímos, sobre todo por la religión. ¡Esta es la causa culminante de la decadencia moral! ${ }^{31}$

En cambio, en España y Portugal predominaría una defensa de la ortodoxia que se articuló en el partido papista. Su punto principal era que las iglesias locales de España y Portugal no pertenecieron a dicho partido en un inicio y la prueba la colocó en el ejemplo del obispo de Braga, el dominico portugués Bartolomé de los Mártires, quien participó en el Concilio en 1561 o el caso de Diego de Álava, obispo de Astorga y el obispo de Cádiz, Jerónimo Teodoli, asociados también a puntos de vista reformistas o ecuménicos. Más bien, consideraba que los tres combatían en defensa de las iglesias peninsulares frente al «Ultramontanismo invason ${ }^{32}$.

Las consecuencias que desprendió de este análisis preceden, en buena medida, al clásico estudio de Max Weber sobre la Ética protestante y el espiritu del capitalismo (1905), pues Antero está hablando ya en 1871 que los pueblos donde triunfó la Reforma han tenido los mayores avances y progresos morales de la civilización: son las naciones más inteligentes, más moralizadas, más pacíficas y más industriosas según sus palabras, y ahí cita a Alemania, a Holanda, a Inglaterra, a Estados Unidos (país con el que Weber curiosamente inicia su análisis a partir de Benjamin Franklin) y Suiza. En cambio, las naciones decadentes serían las católicas, en concreto España y Portugal, donde si hubiera triunfado el partido reformista y no el partido papista, «seríamos libres,

\footnotetext{
${ }^{30}$ Ibídem, 67.

31 Antero de Quental, Causas de la decadencia, 69. Aunque su diagnóstico del Concilio de Trento hoy resulta historiográficamente inexacto, llama mucho la atención que Antero de Quental afirmara que el fundamento de la decadencia es la religión, y además la católica o romana, lo cual es en cierto sentido el resultado más avanzado sobre dicho tema. Hoy en día se sabe que la monarquía hispana decayó no por causas económicas o políticas directas, sino precisamente por la religión. Fue la Iglesia de Roma quien le confirió el poder con el que consiguió su grandeza y fue ésta misma la que, al lograr imponer su espiritualidad en el siglo XVII, se lo arrebató; debilitándola desde sus bases y poniéndola a merced, ahora sí, de las potencias políticas y económicas de Europa. Este diagnóstico puede verse en José Martínez Millán, El mito de Faetón o la imagen de la decadencia de la Monarquía Católica (Granada: Ediciones de la Universidad de Granada, 2011), 9.

32 Antero de Quental, Causas de la decadencia, 74.
} 
prósperos, inteligentes, morales... ipero Roma habría caído! Roma no quería caer. Por eso resistió tanto tiempo [...] $\rangle^{33}$.

En esta dialéctica, donde se impuso la intolerancia y la ortodoxia de dicho partido, «católico» como él lo llama, provocó la Guerra de los Treinta Años y los jesuitas apoyaron este proceso. Incluso -agregó, para no solo hablar de España y Portugal, sino también de Polonia- en 1648 el Rey Juan II Casimiro, quien antes había sido jesuita, quiso obligar a los campesinos rutenos que seguían el cisma griego, a convertirse al catolicismo. Estos se aliaron con los cosacos de rito griego y dieron origen a su separación de la federación polaca y su inclusión a Rusia; acción que calificaba como una osadía ingenua, al ponerse como enemigos a los cosacos. Por esta razón, Polonia será vista como una «nación» totalmente nulificada en el siglo XVIII ${ }^{34}$.

El catolicismo era para él una esfinge que seducía a las naciones y luego devoraba a los pueblos enteros. La Inquisición debilitó enormemente a España y a Portugal en el sector comercial y agrícola, al expulsar a los judíos y a los moros. Los capitales se diluyeron con la persecución de los cristianos nuevos o conversos y, como también se instaló en el Nuevo Mundo, provocó ahí todavía más hostilidades e impidió una colonización sólida; incluso despoblando las Antillas al arrasar a las poblaciones indígenas de dichos lugares ${ }^{35}$. No tenía en cuenta que a principios del siglo XVIII el Consejo de Inquisición era uno de lo más fuertes en términos económicos.

En cambio, Quental condenó a la educación jesuítica, pues la veía como una fuente corruptora del espíritu crítico que exigía en su generación. De esta forma, denunció la pasividad que los padres de la Compañía fomentaron en los indios de las Misiones del Paraguay. Eran, en suma, el símbolo de un absolutismo espiritual que se imponía sobre el poder civil:

[...] el cristianismo existió y puede existir fuera del catolicismo. El cristianismo es sobre todo un sentimiento; el catolicismo es sobre todo una institución. El primero vive de la fe y de la inspiración, el otro del dogma y de la disciplina. Toda la historia religiosa hasta mediados del siglo XVI no es más que la transformación del sentimiento cristiano en la institución católica $[. . .]^{36}$.

Antero seguía la historiografía que asociaba por igual la monarquía con el papado, sin entender las propias dinámicas de cada una (incluyendo el propio funcionamiento del Papado como un reino ${ }^{37}$ ). Así, consideraba que las monarquías de España y Portugal se basaron en la defensa de los intereses de Roma. Concedía un valor extremo a los inquisidores y al papado, poniéndolos en la cima de la escala

33 Ibídem, 74-75.

34 Ibídem, 83. Una explicación adecuada y actual de este proceso y de la dinastía de los Vasa y su relación con el Papado, puede verse en el trabajo de Miguel Conde Pazos, La monarquía católica y los confines orientales de la cristiandad. Relaciones entre la Casa de Austria y los V asa de Polonia, (Tesis Doctoral, Universidad Autónoma de Madrid, 2016).

35 Antero de Quental, Causas de la decadencia, 85.

${ }^{36}$ Ibídem, 70.

${ }^{37}$ Tal como queda plasmado en el libro ya clásico de Paolo Prodi, El soberano pontifice. Un cuerpo y dos almas: la monarquía papal en la primera Edad Moderna (Madrid: Akal, 2011). 
cortesana y calificó a los monarcas traicionar a sus propias naciones. Invitaba, por lo tanto, a abandonar ese espíritu del catolicismo de Trento cuya pervivencia todavía notaba en el siglo XIX y que impedía el triunfo del republicanismo.

El segundo factor, consecuencia de la espiritualidad, es el absolutismo. Mientras que en la Edad Media hablaba de la vida foral y de las instituciones populares representadas en las cortes, pues «la libertad era entonces el estado normal de la península» ${ }^{38}$; todo cambió en el siglo XVI y el poder absolutista arruinó la vida municipal. El ejemplo paradigmático en este caso era la lucha de las comunidades de Castilla, donde triunfaría la centralización monárquica.

Al seguir políticas cesaristas Felipe II intentó el proyecto, que Antero calificó como absurdo, de conquistar Inglaterra y si no se hubiera adoptado el absolutismo, no habría perdido tantas vidas en la derrota de la armada invencible. Lo mismo podía decir el Rey Don Sebastián en la batalla de Alcácer Quibir. Ante esto, oponía de forma idealista a las otras monarquías, como Francia. En este punto mostró un esquema paralelo al de Michelet donde el pueblo es el protagonista de la historia. En cambio, lamentaba que en España y en Portugal predominó un «espíritu aristocrático» que impidió el desarrollo de las ciencias, ni del comercio ni de la industria ${ }^{39}$.

El tercer elemento o causa de la decadencia, de tipo económico -porque la anterior, en tanto absolutismo, era política- fueron las conquistas. Aunque reconocía que tenían un impulso intrépido que permitió a Camões escribir su gran poema épico, el objetivo central era que las naciones modernas funcionaran a partir del fomento de la ciencia y no mediante el cultivo de la poesía. En sus propias palabras: «Quien domina no es ya la musa heroica de la epopeya; sino es la Economía Política, la Calíope de un mundo nuevo, que, si no era tan bella, por lo menos sí era más justa y lógica que la

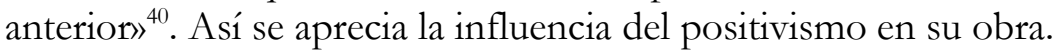

El problema principal, para Antero, no era la conquista en sí misma, sino que se llevaron a cabo conquistas sin procesos de civilización ${ }^{41}$. Incluso llegó a justificar la conquista de la India por los ingleses por dicho parámetro, con tal de criticar la propia de los portugueses en dicho territorio o la de los españoles en América; donde se causaron muchos vilipendios y atrocidades: «iDos imperios prósperos desaparecieron en menos de 60 años! ¡En menos de 60 años fueron asesinados diez millones de hombres! Estos algoritmos son trágicos y no necesitan ningún comentario aparte» ${ }^{42}$.

El análisis general de Antero de Quental seguía la línea de la evolución histórica de las naciones, de la ya consolidada antropología de los pueblos como método de

38 Ibídem, 88.

39 Ibídem, 91-92. Sobre el concepto de pueblo y su reinvindicación en la historia, escribieron el propio Jules Michelet, Elpueblo (México: Fondo de Cultura Económica, 2005) y ya en el siglo XX, Eric Wolf, Europa y la gente sin historia (Buenos Aires: Fondo de Cultura Económica, 2005).

40 Ibídem, 93.

${ }^{41}$ Salvando la distancia temporal, esta conexión entre conquista y civilización empata con la teoría del acortesanamiento de los guerreros y la interrelación y el comportamiento sociales; según lo explicó Norbert Elias, El proceso de la civilización. Investigaciones sociogenéticas y psicogenéticas (México: FCE, 1989).

42 Ibídem, 103. 
reflexión y estudio ${ }^{43}$. Esto le permitió generar categorías como «catolicismo absoluto», «absolutismo monárquico» $\mathrm{y}$ «espíritu aristocrático» con las cuales podía denunciar los problemas de su propia época, dentro de los cuales destacaba el educativo.

Pensaba con ello que el espíritu moderno podría llegar a la sociedad portuguesa del último tercio del siglo XIX con el fomento de una conciencia de libertad y progreso y, dado que se trataba de un problema educativo - por lo tanto, espiritual- hacía mucho ahínco en que, regenerando la desviación histórica del pueblo portugués, sería posible crear un nuevo mundo civilizado: «el cristianismo fue la revolución del mundo antiguo: la revolución no es más que el cristianismo del mundo moderno» ${ }^{44}$. La dimensión ideológica, o espiritualidad, para Antero de Quental, le permitió conciliar una actitud optimista en relación con el progreso de la civilización y la consolidación de la modernidad -siempre en clave europea-. La cultura sería un elemento clave para superar los obstáculos históricos que habían impedido la participación de Portugal en el concierto de las naciones avanzadas.

\section{LA EVOLUCIÓN DEL PENSAMIENTO DE OLIVEIRA MARTINS}

El otro gran teórico sobre la decadencia de Portugal y de los pueblos ibéricos fue el pensador socialista Joaquim Pedro de Oliveira Martins (1845-1894). Aunque ideológicamente se puede afirmar que desarrolló una de las teorías más profundas sobre el socialismo en la península ibérica -un socialismo no marxista-, también se le puede relacionar con el liberalismo republicano que venía desde la época de Garrett; siempre y cuando se tenga en cuenta qué tipo de liberalismo es el que profesó. En cierto sentido, como explica Pedro Calafate, se distancia de los liberales de su generación y acuña más bien una concepción naturalista del tiempo fundamentada sobre todo en una moral; siguiendo así la estructura de la Scienza Nuova de Vico ${ }^{45}$ tanto para su concepción del socialismo como para su particular análisis de la decadencia.

En otras palabras, Oliveira no concebía como sus compañeros de la generación setentista una oposición entre naturaleza y cultura, quienes consideraban a ésta última como el producto del proceso civilizatorio. Más bien, Oliveira pensaba en un primer momento que la civilización era el resultado del triunfo de la naturaleza, tanto a nivel de pensamiento como en la acción. Ya en sus últimas obras, después de efectuar el análisis de la decadencia ibérica con un carácter «pesimista»; hizo un viraje en su forma

\footnotetext{
${ }^{43}$ Esta corriente de análisis, como se mencionó anteriormente, surgió en la tradición alemana y, aunque se ha mencionado a Wundt como uno de sus principales impulsores, no hay que dejar de mencionar los estudios de psicología de Lazarus y Steinthal y su difusión el panorama intelectual europeo a mediados del siglo XIX.

44 Ibídem, 108. Su proyecto político apuntaba a la recuperación de las libertades e igualdades en el marco de la democracia y si éstas en el pasado existían y se habían conseguido a través de la revolución, una revolución democrática, era necesario seguir los ejemplos de la historia. No solamente ponía el ejemplo de los comuneros de Castilla, sino sobre todo estaba influido por la revolución de 1868 de España y el concepto de sufragio universal que se fraguó a partir de la misma. De esta forma, apuntaba a un gobierno federativo que se impusiera a través de la vía del progreso y de la civilización. Antero de Quental, Prosas sócio-políticas (Lisboa: Imprensa Nacional Casa da moeda, 1982), 218, 227.

45 Pedro Calafate, "A reflexão sobre Portugal na viragem do século”, 29-34.
} 
de concebir el ciclo de la naturaleza y ya no lo vio más como un productor de la cultura. Entendió que el proceso civilizatorio solo conllevaba a una ley de egoísmo y de rechazo ante la realidad social. El refugio que encontró, por lo tanto, radicaba únicamente en la interioridad y la estética, de forma parecida al caso de Schopenhauer ${ }^{46}$.

Aunque se le ha colocado en la órbita historiográfica de Alexandre Herculano, autores como Wheeler describen a Oliveira más bien como un difusor del pasado antes que un auténtico historiador, debido a la incorporación de las entonces nuevas ciencias sociales como la antropología física y la ya mencionada psicología de los pueblos -que el propio Wheeler califica, a mi modo de ver, erróneamente como una teoría racial pseudocientífica $-{ }^{47}$; puesto que en su crítica no contempla que el concepto de raza se refería más a una comunidad política.

Además de no incluir en su análisis la relación discursiva con los otros autores y el contexto sociopolítico en el que se desarrolló la introducción de las ciencias sociales en Portugal, el hecho de evaluar el legado de Oliveira como el «cantante de las miserias nacionales» ${ }^{48}$ no incluye la evolución de su pensamiento político e historiográfico. Aunque en algunos pasajes de la Historia de la civilización ibérica, efectivamente, adquiere un tono pesimista, esto no agota el alcance de sus propuestas.

No cabe duda que la Historia de la civilización ibérica es su obra más importante para conocer su visión en torno a la cultura de España y de Portugal, pero no es posible quedarse solo ahí -si se pretende conocer con mayor efectividad el contenido general de sus propuestas-. Una de las características centrales que vuelven a Oliveira un pensador tan original es, que a diferencia de sus compañeros del 70, fue autodidacta. Además fue, junto con Antero de Quental, el autor portugués de dicha generación que dedicó más textos a la cultura española, lo que le permitió hacer una reflexión en conjunto sobre la historia de la cultura ibérica. Sin embargo, un par de años después, en su obra Portugal Contemporáneo se decantó a efectuar una crítica sociológica y cultural de su propio siglo ${ }^{49}$.

\subsection{El heroísmo renacentista}

Para comenzar el análisis de las ideas de Oliveira, se propone revisar en primer lugar su estudio de 1872 Los Lusiadas y el Renacimiento en Portugal. El pensador socialista colocó a la obra maestra de Camões al mismo nivel que el Quijote, los dramas de Shakespeare y la obra arquitectónica de la Basílica de San Pedro de Roma. Por una parte, la obra cervantina la definía como un «tratado de escolástica y casuística, un curso de literatura caballeresca y los primeros principios de una filosofía del sentido común»; mientras que, por la otra, «Los Lusiadas correspondían a la propia epopeya

\footnotetext{
46 Pedro Calafate, "Oliveira Martins", en Histórica do Pensamento Filosófico Português. Volume IV. O Século XIX. Tomo 1, Dir. Pedro Calafate (Lisboa: Editorial Caminho, 2004), 179, 184.

${ }^{47}$ Douglas Wheeler, Republican Portugal, 7.

48 Ibídem, 8.

${ }^{49}$ Calafate, Portugal como problema, 141-143, 188.
} 
de la ciencia, cosmográfica, geográfica y legendaria, una Biblia de la civilización y el símbolo artístico del Renacimiento político» ${ }^{50}$.

Antes de hablar de la «historia de la civilización ibérica» en su obra cumbre, en este ensayo -siguiendo explícitamente las categorías de Burckhardt y de Guizot-, Oliveira mostraba mucha admiración por la «civilización en el Renacimiento», en la línea de la obra clásica del historiador suizo. Si el gran impacto que heredó Portugal al mundo fueron los descubrimientos marítimos, su gran profeta era el gran poeta épico, quien describió el «alma colectiva» y el «optimismo idealista conforme se expresaba el carácter nacionalı ${ }^{51}$.

Camões era para Oliveira el «Paráclito» que se asomaba todavía en el siglo XVII y que se esperaba encontrar en las sucesivas operaciones de descubrimientos y conquistas. En este punto no tuvo ningún reparo en asumir las tres notas que Antero de Quental había distinguido como causas de la decadencia: el imperialismo político, los descubrimientos y las conquistas y el absolutismo religioso. Esta crítica era necesaria para transitar de la Edad Media a la modernidad que representaba el concierto europeo. Oliveira veía cristalizados en aquellos sueños imperiales la definición de Burckhardt del «estado como una obra de arte», expresados por ejemplo en las políticas de Juan II de Portugal, o principe-perfeito, al cual el propio Oliveira le dedicaría un estudio que no alcanzó a finalizar ${ }^{52}$.

Por una parte, el historiador de la civilización ibérica se mostraba profundamente admirado por la estética del poeta épico; pero, por otro lado, compartía la radicalidad de Antero de Quental frente a la decadencia. De esta forma, también notaba la centralización y las desigualdades generadas por el mundo cortesano y distinguía en Camões (o eso pretendía encontrar en su texto) una condena del principio aristocrático de la herencia propia del estamento de los hidalgos:

La corte, en efecto, lo absorbía todo. Lisboa era su lujo, su río, su Tajo, la puerta abierta sobre el tesoro de Oriente, devoraba al reino, en el cual durante varios siglos sus gobernadores gozaron de incesantes beneficios, para aprovechar y cultivar los campos, pero al mismo tiempo restaurando la miseria en la que las guerras moriscas los habían dejado ${ }^{53}$.

Así veía dibujadas en los versos lusiadas las cuentas generadas por el crecimiento de la nación, incluyendo su destino incierto y sus empresas fallidas. Camões aparecía atrapado entre sus himnos pro-imperiales y la consecuente llamada de atención que le generaban sus desviaciones, tal como el otro gran poeta Gil Vicente representaba las desventajas económicas que estaba causando la conquista de la India en la propia «metrópolis». Mientras que los castellanos, dice Oliveira, desarrollaron la picaresca como crítica cínica a su decadencia; los portugueses lloraron la suya con

50 Oliveira Martins, Os lusiadas e a Renascença em Portugal (Porto: Livraria Internacional de Ernesto Chardron, 1891 [1872]), 14.

${ }^{51}$ Ibídem, 32.

52 Ibídem, 128.

53 Ibídem, 132. 
profunda tristeza. Empero, lo hacían con un tono lírico y elegiaco, incluso el propio Camões. A través de su obra observaba cómo el imperio se corrompía en tiranía y, aun en esa melancolía, intentaba llamar a la nobleza a la lealtad de la nación, disolviendo lentamente el heroísmo que había añorado ${ }^{54}$.

Dentro de todos estos cambios de panorama y de paradigma y dentro de dichas denuncias encubiertas, Oliveira desprendía una intuición cosmopolita en el pensamiento de Camões: portugueses eran todos, de la misma forma que en el imperio romano - por pura ficción jurídica- todos eran romanos gracias al principio de la familia (nuevamente se aprecia aquí la crítica a la base del sistema cortesano, que ya intuía adecuadamente Antero). Ese espíritu lo encontraba también en España, pero decía que allí apareció de forma fortuita; mientras que para los portugueses ese era su principio orgánico y constitutivo. Para el portugués -desde el siglo XVI-, atribuía ya un «patriotismo cívico» que se volvió un ideal ${ }^{55}$.

\subsection{El naturalismo ibérico: auge y caída de su civilización}

En su gran obra, que Miguel de Unamuno recomendaba leer a todos los españoles y portugueses, la Historia de la civilización ibérica (1879), Oliveira Martins ofreció una continuidad de esa teoría del heroísmo peninsular que había proscrito anteriormente; pero hizo más hincapié en las teorías evolucionistas y naturalistas que se aplicaban a los pueblos y a las naciones -incluyendo, desde luego, la idea de la decadencia-. Al mismo tiempo, aunque se corresponde con una ideología liberal, su intención consistía en mostrar el desarrollo histórico de España y Portugal en sus dinámicas internas e independientes para crear su propia memoria. El contexto geopolítico, en cambio, padecía una predominancia mercantil y simbólica de las culturas anglosajonas ${ }^{56}$ (tema que perdurará en su crítica).

Puso mucha atención en rebatir la interpretación del historiador inglés Henry Thomas Buckle -autor de la Historia de la civilización en Inglaterra-; quien aplicaba ciencias como la mesología para explicar que los pueblos ibéricos eran propensos al miedo por ser principalmente culturas bucólicas. En cambio, Oliveira quería resaltar una base heroica y entusiasta de las clases populares en España y en Portugal; con la salvedad, y esto lo distingue de Antero, que no las contraponía frente a la aristocracia, sino que las veía en una relación de soporte y representatividad ${ }^{57}$. En este sentido, vale la pena

\footnotetext{
54 Ibídem, 187, 261-262.

55 Ibídem, 301, 304. Un ideal que perfiló toda una mitología de carácter providencialista y que fungió como elemento aglutinador de una identidad para el pueblo portugués desde el siglo XIX. Al mismo tiempo, esa noción de pueblo se recubrió de una mitología nacionalista; la misma que fue tergiversada durante la dictadura de Oliveira Salazar. Eduardo Lourenço, O Laberinto da Saudade (Lisboa: Gradiva, 2013), 58-66; Miguel Reale, Traços fundamentais da cultura portuguesa (Lisboa: Planeta, 2017), 139-153.

56 Sérgio Campos Matos, "Una perspectiva peninsular y transnacional sobre España y Portugal”, en Joaquim Pedro de Oliveira Martins, Historia de la civilización ibérica (Pamplona: Urgoiti Editores, 2018), XXVII.

${ }^{57}$ Joaquim Pedro de Oliveira Martins, Historia de la civilización ibérica, 22-23. Para una revisión de la sutil y discreta polémica entre Antero de Quental y Oliveira Martins, véase el prólogo de Joel Serrão a
} 
identificar y ver por separado: 1) su lectura de la guerra de las comunidades de Castilla; 2) su reinterpretación del poder real y 3) el énfasis en el misticismo ibérico para la conformación de la espiritualidad de dichas monarquías.

Si la historiografía romántica y la versión de Buckle sobre los comuneros de Castilla los colocaban como mártires populares frente al poder real y el poder eclesiástico; Oliveira resaltó, en cambio, que fue el espíritu de independencia el que se desplegó en dichos movimientos: pero en un pacto civil con el poder real. Según la historiografía que combatía, dicho heroísmo popular fue destruido por el absolutismo (el cual ya comenzaba desde las políticas imperiales de Carlos V) y con ello empezaría la decadencia. Sin embargo, él leía el movimiento comunero en una clave donde no se condenaba a priori el sistema cortesano y se aventuraba a entender a los actores sociales dentro de sus propios estamentos y de acuerdo al periodo de evolución histórica que transitaban:

Ahora bueno es saber que Padilla era hidalgo y que en Villalar la unión derrotada era, en su mayor parte, aristocrática. Carlos $\mathrm{V}$ dio a los plebeyos el derecho de usar la espada para defenderse de los nobles. La deplorable confusión que se hace de la historia y de la política, llevando a la primera las preocupaciones de la segunda, viendo un tirano donde quiera que había un rey, un salteador donde existía un noble, un charlatán allí donde se encontraba un sacerdote; ese deplorable defecto confunde todo, todo lo revuelve, haciendo casi imposible la comprensión de las cosas ${ }^{58}$.

Para Oliveira, la guerra de las comunidades de Castilla constituía el paso de la Edad Media al Renacimiento. Se negaba a sostener que la monarquía y el catolicismo de la península ibérica fuesen contra la naturaleza y, por esta razón, los insertaba dentro del proceso de evolución histórica de los pueblos. Después de la guerra, no hubo protestas - a pesar de la condena a muerte de varios líderes comuneros-, sino una serie de pactos y acuerdos entre los estamentos que estaban en pugna. El filósofo portugués quería, de esta manera, quitar la impronta de identidad del trono y el altar que en España había subrayado Don Marcelino Menéndez y Pelayo; en aras de localizar la historia en los nuevos discursos científicos:

En vez de condenar, expliquemos. Si el trono y el altar no pueden ser ya símbolos expresivos de nuestro pensamiento; si la monarquía y el clero no pueden ser, a lo sucesivo, los instrumentos de nuestra voluntad; si las nuevas ideas e instituciones vinieron a sustituir a las antiguas, no vamos por eso a cambiar la plácida integridad de la ciencia, la luminosa serenidad de la crítica, por los entusiasmos de nuestro espíritu revolucionario, por la intolerancia de nuestras doctrinas. En la historia no hay enemigos, hay muertos. La crítica no es una discusión, es una sentencia ${ }^{59}$.

las Prosas socio-políticas: "Génese e estrutura do pensamiento sócio-político de Antero de Quental", 78-86.

${ }^{58}$ Oliveira Martins, Historia de la civilización ibérica, 24-25.

${ }^{59}$ Ibídem, 26. 
El segundo punto con el que discutió fue el mismo que Antero subrayaba reiteradamente sobre la sumisión de las monarquías de España y Portugal a la Iglesia de Roma. Oliveira explicó que el cristianismo de los reyes Juan III de Portugal y Felipe II de España era bastante acentuado, pero en calidad de «reyes-sacerdotes $»^{60}$; puesto que concentraban en sus potestades reales la espiritualidad de los súbditos-feligreses, es decir, del pueblo. En suma, en el siglo XVI no había una separación entre la política y la religión.

Oliveira era consciente del carácter simbólico de su propuesta y sabía que éste le ayudaba a dar una explicación diferente al propio sistema de corte. Para él, en la Edad Moderna la «soberanía nacional» residía en los reyes, sobre todo en los siglos XV y XVI y, por lo tanto, la monarquía contenía un carácter democrático paradójicamente-. Todo esto era parte de una evolución orgánica de la civilización ibérica que iba avanzando en su ideal socialista.

Si bien le atribuía un carácter muy estricto a la naciente historiografía como ciencia social, sus intuiciones sobre la historia de la monarquía hispana resultan muy distintas al carácter pesimista que se le suele atribuir a su pensamiento. Incluso su visión de Carlos $\mathrm{V}$ está situada en el contexto de la consecución paulatina de la soberanía de España. El primer paso para conseguirlo, en su lectura, era la toma de conciencia de Carlos V que debía dejar de ser un rey extranjero y «nacionalizarse», o en términos de la corte, «castellanizarse» ${ }^{61}$. Esta fue una de las principales consecuencias de la guerra de las comunidades de Castilla y no se relaciona, en absoluto, con la idea clásica sobre la decadencia.

La centralización -que para sus compañeros del Cenáculo era una de las aberraciones principales de la Edad Moderna- tampoco era un factor negativo desde su propia óptica: se trataba del resultado del patriotismo de los soberanos en relación a las demandas populares. El principio de la Razón de Estado estaba, así, revestido de una moralidad simbólica que le confería un carácter judiciario a la envestidura del monarca (pero que también respondía a las dinámicas de las sociedades) ${ }^{62}$. Como seguía un esquema organicista, la Monarquía sería el corazón que le daría vitalidad a todo el cuerpo social, encontrando así aperturas en el propio sistema cortesano. Había, pues, una unidad que le daría su identidad a la monarquía:

Si [la Monarquía] destruyó las inmunidades municipales, no fue por cariño a la nobleza, sino porque con ellas la clase media reproducía las formas aristocráticas. La Monarquía está al frente de una democracia; ya no hay privilegios ni linajes y, como en la antigua Roma, la aristocracia procede de las acciones, no de la sangre: el sacerdocio, la guerra, la administración, ennoblecen, y sus puestos son asequibles a todo hombre del pueblo, a todo hijo de siervo que se crea capaz de hacerse hidalgo: Pizarro era un guardador de puercos; Jiménez, de humilde fraile, convirtióse en casi rey de Castilla. Se renueva

\footnotetext{
${ }^{60}$ Ibídem, 129. Lo cual, hasta cierto punto, se corresponde con el proceso de confesionalización, a través del cual la monarquía hispano-portuguesa (de Felipe II) consolidó su poder y aplicó un disciplinamiento social. Martínez Millán y de Carlos Morales, Religión, política y tolerancia, 134.

${ }^{61}$ Oliveira Martins, Historia de la civilización ibérica, 139.

62 Ibídem, 141.
} 
la aristocracia, y los segundones van a la guerra en busca de honores, títulos y riquezas $^{63}$.

El tercer y último elemento que detectó en su análisis del carácter del «genio ibérico» fue el misticismo, sobre todo el español. De éste subrayaba que, a diferencia de la espiritualidad romana, no tenía un trasfondo abstracto o filosófico, sino naturalista y moral. Esta sería la base del espíritu de los descubrimientos y del heroísmo, de la constitución de la soberanía nacional en el modelo cortesano y del carácter independiente de los pueblos ibéricos. El misticismo colocó a la península en el centro de atención de la Europa moderna durante el siglo XVI, lo que le permitió oponerse al espíritu protestante. El espíritu místico desembocó en la ortodoxia jesuítica, pero ahí no estaba la esencia de la civilización ibérica:

[...] el espíritu moderno, racionalista y científico, no procede directamente ni de uno ni de otro de los dos partidos. Su origen está en el siglo XVI, entre ambos y al lado de la lucha. Nuestros legítimos ascendientes no son los jesuitas ni los protestantes; son los humanistas, que, con Erasmo al frente, comprendían los peligros y la inutilidad de esas discusiones, arrancadas del fuero íntimo e individual de la metafísica para el colectivo de la conciencia religiosa, donde producían dos alucinaciones diversas en su aspecto, pero igualmente perversas, igualmente inútiles: el formalismo católico de los jesuitas y el delirio protestante de los anabaptistas ${ }^{64}$.

Oliveira hablaba de un catolicismo en su sentido etimológico, es decir, universal. Así ubicaba el espíritu de San Ignacio de Loyola en el siglo XVI, lo que justificó el espíritu de conquista en este siglo. Con la expansión de la religión, de modo semejante a la empresa colombina en América, fue adquiriendo una dimensión no nacional. Sin embargo, conforme se iba implantando o renovando la cristiandad europea, fue surgiendo una oposición entre el genio ibérico, místico y heroico; frente a la teocracia papal basada en la obediencia, que adoptaría el jesuitismo para sus propios intereses ${ }^{65}$. En este sentido, el autor distinguía que las monarquías hispana y portuguesa no estaban subordinadas al Papado en el siglo XVI y como prueba de ello es que el Consejo de Inquisición era regido por la monarquía, aun a pesar de la oposición pontificia. A diferencia de Antero, él ya tuvo en cuenta esta distinción historiográfica.

El Concilio de Trento no sería la pérdida de las libertades y autonomías de las monarquías ibéricas, sino la gran campaña de Carlos V, continuada por Felipe II, para imponer en Europa la religiosidad ibérica que ellos propugnaban a través de la espiritualidad de la que se habló anteriormente. De hecho, Oliveira consideró que los resultados del Concilio - debido a las presiones de los reinos protestantes- arruinaron el proyecto de Carlos V, por el descontento que causó en Europa y en el seno de Roma. No era un asunto meramente español, sino europeo. Al final, se impuso el espíritu de

\footnotetext{
${ }^{63}$ Ibídem, 142.

${ }^{64}$ Ibídem, 156.

65 Ibídem, 163.
} 
obediencia jesuita, el cual contrastaba con el plan original humanista que lo había convocado ${ }^{66}$. La relación entre humanismo e imperio resulta una de las claves fundamentales que el filósofo aportó en su lectura del reinado de Carlos V.

En su reflexión final, el historiador portugués describió que estos intentos del siglo XVIII por restaurar la hegemonía del siglo XVI crearon el paso del terror político o monárquico al terror religioso, precio que debían pagar los ministros ilustrados para reincorporarse al camino de la cultura y la ciencia europeos. Desde su punto de vista, este cambio político no surgió del genio ibérico, sino de un deseo personal que terminó por establecer un régimen de represión y absolutismo; con tal de restablecer los principios naturalistas que habían sido objeto de admiración de toda la Europa del siglo XVI.

En una obra que fue publicada en el mismo año (1879) dedicada a la Historia de Portugal, Oliveira mostró un tono muy crítico, en contraste con el armonicismo y la evolución histórica que había planteado anteriormente. Denunció las desviaciones morales de la cristiandad y del estamento eclesiástico; cuya corrupción arrastró el misticismo positivo del siglo XVI y cuya debacle se pronunció con la educación jesuítica. Siguiendo la estructura organicista, arremetió aquí contra la Inquisición, al presentarla como un cuerpo policiaco que tenía la autoridad de un tribunal; generando así un «cesarismo de Estado» ${ }^{67}$. Cultura y naturaleza aparecían, finalmente, disociadas en su pensamiento y, por esta razón, condenó a la Edad Moderna como tres siglos de «política fantástica del romanismo dantesco» ${ }^{68}$.

La visión historiográfica de Oliveira estaba conscientemente sesgada para explicar los problemas de su tiempo que encontraba persistentes y que los remontaba a un periodo o acontecimiento de la Edad Moderna. Su teoría socialista y evolutiva era un medio con el cual podía medir el atraso económico, político y sobre todo cultural. No esperaba encontrar fantasmas en la historia, ni crearlos; sino recrear su sentido simbólico y conferirle una explicación científica que le permitiera continuar en la senda del progreso decimonónico - proyecto que finalmente le provocó más dudas que certezas-.

66 Ibídem, 168-169. Para Pedro Calafate, tanto Oliveira como Antero llevaban razón sobre el Concilio, aunque cada uno lo observara desde un ángulo distinto. El Concilio, que desde la monarquía hispana se posicionaba en contra de la Reforma, defendía el valor de las acciones humanas en torno a la salvación; la cual Lutero solo la reducía a la fe. «En Trento se afirmó el valor ético de las obras, pero se sublimó el valor de la autoridad eclesiástica en la mediación entre la conciencia individual y la divina». Calafate, Portugal como problema, 228.

${ }^{67}$ Joaquim Pedro de Oliveira Martins, História de Portugal (Lisboa: Guimaraes, 2004) 250-252.

${ }^{68}$ Joaquim Pedro de Oliveira Martins, Theoria do socialismo (Lisboa: Guimaraes, 1952) 151. 


\section{BALANCE DESDE LA METODOLOGÍA DE LA CORTE}

\subsection{Portugal resituado en la balanza europea}

Gracias a las nuevas metodologías y conocimientos historiográficos, ha sido posible desprender de los relatos decimonónicos los prejuicios propios de su época muchas veces revestidos de un carácter de cientificidad-. No obstante, se ha intentado demostrar que varias intuiciones propuestas por los principales filósofos de la generación de 1870 obedecían a una nueva lectura de la historia, apoyados en las metodologías que les ofrecían las incipientes ciencias sociales.

Leyendo los estudios de Félix Labrador, se puede entender que Portugal -en tanto reino cristiano que poseía su propia legislación desde la Edad Media- estructuró por sí misma su monarquía; a través de la consolidación del servicio cortesano en la Casa Real. Esto no cambió con el reinado de Felipe II, quien respetó e integró a las élites locales a través de relaciones no institucionales; con lo cual pudo mantener el orden social y compensar la ausencia física del Rey de España ${ }^{69}$.

Ya anteriormente el profesor Fernando Bouza escribió que uno de los principales elementos que permitió articular la Casa Real portuguesa fue la decisión de respetar el derecho de los portugueses a consultar la «gracia real» y además hacerlo en lengua portuguesa. De esta forma, la Monarquía tenía un solo príncipe que reinaba sobre una pluralidad amplia de dominios. La crisis portuguesa surgiría en el momento en que no fue posible mantener esa estructura a mediados del siglo XVII, dentro de muchos otros factores, por el descontento generado a raíz de las decisiones de Olivares y Felipe III que afectaron los intereses de las élites portuguesas ${ }^{70}$.

Parte de esos descontentos era el sentimiento de los portugueses de ser tratados como «las Indias de Castilla», aspecto del que siempre renegaron y además se esforzaron por demostrar su no sujeción al imperio en tiempos de Carlos V. Por esta razón, como explicó Pedro Cardim, Felipe II se encargó de concederles mercedes y títulos específicos, conservar la Casa Real, crear el Consejo de Portugal y hasta de aplicar la misma política de confesionalización que había establecido en la monarquía hispana. De esta forma, se puede apreciar que el caso de la monarquía portuguesa tuvo la misma dignidad y pasó los mismos procesos y dinámicas que las otras monarquías europeas, sin ser una excepción ${ }^{71}$ o un caso sociológico distinto.

Las divergencias que los historiadores decimonónicos muestran en sus versiones particulares en cierto grado se deben a las variaciones de los propios testimonios de los autores de la Edad Moderna; que escribían de acuerdo a la facción política cortesana a la que pertenecieran. Algunos, durante el reinado de Felipe II, se sumaron de forma voluntaria y entusiasta al proyecto de la monarquía universal;

\footnotetext{
${ }^{69}$ Félix Labrador Arroyo, La Casa Real en Portugal (1580-1621), (Madrid: Polifemo, 2009), 286, 401402.

${ }^{70}$ Fernando Bouza Álvarez, Portugal no tempo dos Filipes. Política, Cultura, Representações (1580-1668), (Lisboa: Cosmos, 2000), 50-52, 115-120.

${ }^{71}$ Pedro Cardim, Portugal unido y separado. Felipe II, la unión de territorios y el debate sobre la condición política del Reino de Portugal (Valladolid: Universidad de Valladolid, 2014), 16, 53, 94-107, 284.
} 
mientras que otros se mantuvieron descontentos por la unión de 1580. En este sentido, Pedro Cardim ha argumentado que la revuelta de Portugal (ya en el siglo XVII) fue un conflicto promovido por los nobles que se habían visto afectados por Olivares, como se dijo anteriormente: una de las cuales fue la disolución del Consejo de Portugal y buscar sustituirlo con una junta luso-castellana controlada más bien por ésta última.

Después de la austeridad cortesana que llevaron los miembros de la dinastía de los Braganza tras la separación de España (austeridad más bien bucólica, antes que política o económica) los portugueses paulatinamente comenzaron a imitar el modelo francés -sobre todo en el siglo XVIII-, mientras que la corte española fue perdiendo su esfera de influencia que había tenido anteriormente en Europa ${ }^{72}$. Esta versión historiográfica, más reciente, ha querido resituar el papel de Portugal en la historia moderna europea; alejándola de modelos de victimización o determinismos históricos que la relegaban a un papel secundario o a una explosión imperial pasajera.

\subsection{La Corte: teoría y método}

En términos conceptuales, no hay que olvidar, tal como ha enseñado el Profesor Martínez Millán en sus trabajos, que el sistema cortesano debe entenderse como la organización política mediante la cual se articularon los distintos reinos de la monarquía. Este es un elemento importante y novedoso que no aparece en la historiografía liberal del siglo XIX -la cual fue seguida todavía hasta mediados del XX-, donde se insistía sobre la «falta de libertades» que la dinastía de los Austrias había dejado en la península ibérica. Por eso aparecían recurrentemente los tópicos de los comuneros de Castilla y la Inquisición en el discurso de los liberales españoles ${ }^{73}-\mathrm{y}$ ahora, también, como se ha expuesto en estas páginas, en los portugueses-.

La historiografía liberal, siguiendo a Gijs Versteegen, estaba imbuida de un sentimiento romántico que hablaba del espíritu del pueblo (Volkgeist) y quería justificar el surgimiento del Estado para transmitir y enseñar lo que conformaría las historias nacionales. Sin embargo, esta concepción no tuvo en cuenta que la corte era un espacio de sociabilidad humana natural, justificada en la filosofía clásica y luego en la escolástica, que desarrolló su propio lenguaje y sus propias prácticas de funcionamiento ${ }^{74}$.

Este sistema cortesano, propio y exclusivo de la Edad Moderna, entró en decadencia cuando encontró contradicciones en las bases que lo fundaban. Esto afectó tanto a la Corona de Castilla como a la de Portugal en materia económica y política, evidentemente, pero solo como consecuencia de la necesidad de reconfigurar su estructura interna. Si en el siglo XVII la Monarquía ya no era universal, sino católica y, por lo tanto, subordinada a la espiritualidad papal- después de la separación de

72 Pedro Cardim, Portugal y la Monarquía Hispánica (ca. 1550-ca.1715), (Madrid: Marcial Pons, 2017), 50-55, 61-64, 115, 276, 356.

73 José Martínez Millán, “Introducción”, en José Martínez Millán y José Eloy Hortal Muñoz (Dirs.) La Corte de Felipe IV (1621-1665). Reconfiguración de la Monarquía católica, Tomo I, Vol. 1 (Madrid: Polifemo, 2015), 15-16.

${ }^{74}$ Gijs Versteegen, Corte y Estado en la historiografía liberal. Un cambio de paradigma (Madrid: Polifemo, 2015), 9-12, 27,61. 
España y Portugal y tras la desarticulación y el reparto que las principales monarquías europeas y el Imperio de Viena planeaban sobre España y Portugal, estas coronas necesitaban una nueva justificación ${ }^{75}$. Portugal la encontró mediante los acuerdos con los ingleses, mientras que España adoptó más bien una práctica regalista -que no tenía en cuenta ya ni al Imperio ni al papado-.

La idea de domesticidad había fundamentado el sistema cortesano durante los siglos XVI y XVII, mientras que en el siglo XVIII la Casa Real se reorganizó de acuerdo a otro modelo sociopolítico, cuya noción de la oeconomica se revistió más bien de un carácter metafórico antes que patrimonialista. La metodología de la corte permite situar el principio filosófico y espiritual que subyacía durante las diferentes fases de la Edad Moderna. Evidentemente, se tratan de recursos y categorías historiográficas; pero permiten evitar acercamientos políticamente sesgados como los del liberalismo en el siglo XIX.

\subsection{Las tres causas de la decadencia ibérica vistas desde el paradigma cortesano}

Las tres constantes que los historiadores portugueses describieron en sus observaciones pueden reinterpretarse a la luz del punto de vista de la Corte y las Casas Reales como modelo de articulación política durante la Edad Moderna. Como se ha tratado de mostrar en las apreciaciones y comentarios críticos durante la exposición de sus ideas (fuentes primarias de este artículo), Garrett, Antero y Oliveira tuvieron intuiciones que anticiparon lúcidamente las aportaciones que los estudios de la Corte han ido mostrando a lo largo de sus trabajos. El diálogo historiográfico que cada uno estableció en torno a la decadencia de la civilización ibérica contenía ya una reflexión crítica sobre la documentación disponible y este esfuerzo, efectivamente, ha legado los aciertos -aunados a sus propios prejuicios de la época- que colindan con la visión de la corte desplegada a continuación.

El absolutismo político. Los propios estudios de la Corte han permitido poner en cuestión conceptos tan recurrentes como el mismo de Antiguo Régimen y su correspondiente absolutismo; cuidando al mismo tiempo de no caer en las grandes generalizaciones que el método braudeliano impulsa. El proyecto político de construir un gran imperio, que puede corresponder más o menos con la primera globalización, estaba basado en la filosofía política de la monarquía universal. Este concepto viene desde la tradición medieval de Dante Alighieri y fueron los tratadistas políticos y ministros de Carlos V -como el Gran Canciller Gattinara- quienes recuperaron esa noción para justificar el modelo político del Emperador. Este título se agotó al final de dicho reinado en España y en Portugal, pues la corona imperial no le fue heredada a Felipe II, sino al hermano de Carlos, Fernando de Habsburgo.

${ }^{75}$ José Martínez Millán, “Introducción” y “La reconfiguración de la Monarquía Católica (siglos XVII al XVIII)", en José Martínez Millán, Félix Labrador Arroyo y Filipa M. Valido-Viegas de Paula Soares (Dirs.) ¿Decadencia o Reconfiguración? Las Monarquias de España y Portugal en el cambio de siglo (1640-1724) (Madrid: Polifemo, 2017), 1-7; 8-19. 
Felipe II gobernó bajo la ideología política de la monarchia universalis, sin tener el título de Emperador. Para reforzar su proyecto y conseguir este objetivo, llevó a cabo una política de confesionalización, donde la Inquisición tuvo un papel importante -en tanto Consejo Real de la Monarquía- para el control social e ideológico de los súbditos de los diferentes reinos. Su apuesta política pretendía claramente alcanzar el gobierno universal que aspiraba en su justificación filosófica; pero no se puede calificar como un gobierno absolutista en un sentido napoleónico -tal como se solía pensar en el siglo XIX-. Incluso el famoso Rey Sol en Francia, durante el siglo XVII, a quien se suele presentar como el paradigma del absolutismo político, en realidad lo que hizo fue aplicar el esquema de la monarquía universal a su propia expansión política -una vez que Luis XIV derrotó a Felipe IV-.

Descubrimientos y conquistas. Uno de los tópicos presentes en los memoriales de los autores arbitristas reside en presentar a la decadencia de la monarquía como consecuencia del oro de las Indias. Como se ha observado en el pensamiento político de Antero de Quental y de Oliveira Martins, estas nociones persistían y quedaban acentuadas de un modo exagerado. Desde el punto de vista de los estudios de la corte, los arbitristas pertenecían al partido o facción política castellana; la cual defendía el proyecto de la monarquía universal aun después del reinado de Felipe II. El otro partido estaba conformado por el partido papista, cuyos miembros abogaban por una subordinación de la monarquía hispánica y de la portuguesa a la autoridad pontificia.

Los arbitristas tenían una noción muy clara del análisis de la decadencia -más allá de aquellos autores que solo participaban en los debates para obtener réditos por sus arbitrios-. Si se traza una perspectiva desde la metodología de la corte, se puede observar que la decadencia que los arbitristas denunciaban se focalizaba únicamente en Castilla; pero no así en los otros reinos peninsulares ni de Ultramar (salvo lo que en su día el profesor Ernest Lluch denominó como «aragonesismo austracista» en el siglo XVIII). Ni siquiera en el momento más álgido del reinado de Felipe IV, tras perder la Guerra de los 30 años, se podría diagnosticar una decadencia general de todos los reinos.

No obstante, es verdad que el oro de las Indias no se quedó en la península ibérica, sino que fue ocupado para cubrir las deudas contraídas en Europa y financiar la expansión de la monarquía universal. La decadencia comenzó cuando la monarquía abandonó dicha aspiración, dejó de expandirse mediante las armas y optó por intentarlo únicamente a través de la predicación pacífica. El resultado fue la generación de cientos de mártires religiosos que murieron en los reinos orientales; sin un ejército que interviniera -como sí ocurrió en México y en el Perú en el siglo XVII-.

La espiritualidad. La Inquisición. Los jesuitas. Finalmente dentro de esta descripción sintética, el tema de la espiritualidad está relacionado íntimamente con la evolución ideológica de la monarquía. Solo si se tiene en cuenta que no es posible hablar de una monarquía católica en el siglo XVI, sino solo en el siglo XVII, se entenderán las bases ideológicas que rigieron el destino de las monarquías de España y Portugal. Al principio, se aprecia una espiritualidad abierta a los descubrimientos, confesional $-\mathrm{y}$ por eso se incorpora la Inquisición en los reinos ultramarinos- y que 
esperaba coronar al rey de España y Portugal como el señor del Orbe y gran emperador de la cristiandad.

Sin embargo, después de las tensiones entre la monarquía y el papado (que no olvidó nunca el saco de Roma de 1527), desde la sede pontificia se hizo todo lo posible por que abandonaran el proyecto de la monarquía universal. El medio que se eligió desde el Colegio Cardenalicio fue precisamente la educación del joven príncipe (Felipe III) para que abandonara las ambiciones de su abuelo y de su padre y se rigiera por el método de espiritualidad radical o descalzo para construir una monarquía católica, que respetara los intereses del Vaticano.

\section{CONCLUSIÓN GENERAL}

El modelo político cortesano, aunque se expresa en número singular, sufrió diversas transformaciones a lo largo de la Edad Moderna y, por lo tanto, no cabe dentro del uso laxo de las contextualizaciones de la Escuela de los Anales y la metodología de la larga duración; cuya génesis se puede ya ver en la historiografía liberal del siglo XIX. Los cambios estructurales que se producen dentro de un periodo de tiempo determinado deben ser matizados de acuerdo a la ideología que en cada momento los grupos o facciones políticas seguían e imponían en el orden social.

Los historiadores analizados, desde Garrett hasta Oliveira -arco temporal que habría que ampliar para un trabajo posterior, al menos para contrastar la crítica de António Sérgio- estudiaban el llamado Antiguo Régimen desde una distancia ideológica opositora a los autores tradicionalistas; quienes justificaban su admiración a las instituciones cortesanas como un modelo político para su propio tiempo. Ambos extremos ideológicos no pretendían alcanzar una objetividad empírica a partir de sus postulados, aunque recurrieran a las incipientes ciencias sociales para ofrecer explicaciones alternativas a lo que cada sector político identificaba como una historia oficial (que había que poner en cuestión).

A modo de conclusión, se puede afirmar que los procesos historiográficos del siglo XIX que se han analizado a lo largo del texto, muestran efectivamente más información objetiva sobre su propia época que sobre los datos del pasado que pretendían ordenar y reconstruir. No cabe duda que la historia en este sentido, para el caso portugués y español, se volvió un campo de batalla ideológico; donde se reflejaba la sensibilidad romántica y los debates en torno al progreso científico y cultural de las civilizaciones modernas. Como afirmó Jean-Frédéric Schaub, hay que ser muy cuidadosos con las categorías de historia tradicional, conservadora, patria, liberal y romántica; pues cada una va asentando su propia tradición que genera sendas oposiciones. Si se mantiene dicha rigidez, resulta inadecuado e insuficiente el proceso de estudiar el Antiguo Régimen ${ }^{76}$, o, mejor dicho, el sistema cortesano de la Edad Moderna.

${ }^{76}$ Jean-Frédéric Schaub, Le Portugal au temps du Comte-Duc d'Olivares (1621-1640). Le conflit de jurisdictions comme exercice de la politique, (Madrid: Casa de Velázquez, 2011), 1-13, 385-406. 
Frente a esto, se podría agregar que filósofos-historiadores como Oliveira Martins y Antero de Quental fueron hombres de su tiempo que introdujeron las metodologías científicas más avanzadas de Europa y que las aplicaron a su propia realidad geopolítica y cultural. Una vez que se ha entendido el contexto socioeconómico desde el cual escribieron -expuesto en el primer apartado-, es posible apreciar sus reflexiones como incentivos todavía actuales (en tanto generadores de ideas) para comprender de una forma más entrelazada las historias de España, Portugal y América. Quizás las categorías de civilización, progreso y decadencia ya no funcionen en la actualidad; pero su lectura y sus grandes síntesis conduzcan a los historiadores y lectores actuales a modernizar y precisar cada vez más el conocimiento del pasado y de la cultura filosófica que predominó en cada época. 


\section{REFERENCIAS BIBLIOGRÁFICAS}

Bonifácio, Maria de Fátima, Fora da circunstância. Ensaios polémicos sobre grandes questões da actualidade (Alfragide: D. Quixote, 2019).

Bonifácio, Maria de Fátima, História e Ideologia. Uma polemica Novecentista (Lisboa: Editorial Presencia, 2017).

Bouza Álvarez, Fernando, Portugal no tempo dos Filipes. Politica, Cultura, Representações (1580-1668), (Lisboa: Cosmos, 2000).

Braga, Teófilo, Dissolução do systema monarchico constitucional (Lisboa: Nova libraria internacional, 1881).

Calafate, Pedro "Oliveira Martins: as aventuras da História", en Histórica do Pensamento Filosófico Português. Volume IV. O Século XIX. Tomo 1, dir. P. Calafate (Lisboa: Editorial Caminho, 2004), 173-185.

Calafate, Pedro, "A reflexão sobre Portugal na viragem do século", en Filosofía y Literatura en la peninsula ibérica. Respuestas a la crisis finisecular. I Jornadas LusoEspanholas de Filosofía, Lisboa, 2009, ed. P. Calafate, J. L. Mora García y X. Agenjo Bullón (Madrid: Fundación Ignacio Larramendi, 2012), 25-34.

Calafate, Pedro. "Introdução", en Portugal como problema. Século XIX. A decadência. Volume III, ed. P. Calafate (Lisboa: Fundaçao Luso-Americana y Público, 2006), 13-16.

Campos Matos, Sérgio, "Nación. Portugal", en Diccionario politico y social del mundo iberoamericano. La era de las revoluciones, 1750-1850 [Iberconceptos-I], dir. Fernández Sebastián (Madrid: Fundación Carolina/Sociedad Estatal de Conmemoraciones Culturales/Centro de Estudios Políticos y Constitucionales, 2009), 953-966.

Campos Matos, Sérgio, "Una perspectiva peninsular y transnacional sobre España y Portugal", en Historia de la civilización ibérica, Joaquim Pedro de Oliveira Martins (Pamplona: Urgoiti Editores, 2018), VII-XCII.

Campos Matos, Sérgio, Historiografía e Memória (Lisboa: Colibri, 1998).

Campos Matos, Sérgio, Iberismos: nação e transnação, Portugal e Espanba c. 1807-1931

(Coimbra: Imprensa da Universidade de Coimbra, 2017). https://doi.org/10.14195/978-989-26-1368-0 
Cardim, Pedro, Portugal unido y separado. Felipe II, la unión de territorios y el debate sobre la condición politica del Reino de Portugal (Valladolid: Universidad de Valladolid, 2014).

Cardim, Pedro, Portugal y la Monarquia Hispánica (ca. 1550-ca.1715), (Madrid: Marcial Pons, 2017). https://doi.org/10.2307/j.ctvh4zgbm

Conde Pazos, Miguel, La monarquía católica y los confines orientales de la cristiandad. Relaciones entre la Casa de Austria y los Vasa de Polonia, (Tesis Doctoral, Universidad Autónoma de Madrid, 2016).

De Oliveira Martins, Joaquim Pedro, História de Portugal (Lisboa: Guimaraes, 2004) 250252.

De Oliveira Martins, Joaquim Pedro, Politica e economía nacional (Porto: Magalhães \& Moniz Editores, 1885).

De Oliveira Martins, Joaquim Pedro, Theoria do socialismo (Lisboa: Guimaraes, 1952).

De Oliveira Martins, Joaquim Pedro, Os lusiadas e a Renascença em Portugal (Porto: Livraria Internacional de Ernesto Chardron, 1891).

Elias, Norbert, Elproceso de la civilización. Investigaciones sociogenéticas y psicogenéticas (México: FCE, 1989).

Garrett, Almeida, Portugal na balança da Europa; do que tem sido e do que ora the convém ser na nova ordem de coisas do mundo civilizado (Londres: S.W. Sustenance, 1830).

Granville Stapleton, Augustus, George Canning and his times (London: John W. Parker and Son, West Strand, 1859).

Halévy, Elie, A History of English People in the Nineteenth Century. Volume II. The liberal awakening (1825-1830), (London: Barnes \& Noble, 1961).

Hespanha, António Manuel, Visperas del Leviatán (Madrid: Taurus, 1989).

Labrador Arroyo, Félix, La Casa Real en Portugal (1580-1621) (Madrid: Polifemo, 2009).

Lourenço, Eduardo, O Laberinto da Saudade (Lisboa: Gradiva, 2013).

Mandado Gutiérrez, Ramón E. y Bolado Ochoa, Gerardo (Dirs.), La Ciencia Española. Estudios (Santander: Real Sociedad Menéndez Pelayo/Ediciones de la Universidad de Cantabria, 2011). https://doi.org/10.22429/Euc2019.019 
Martínez Millán, José y Carlos Morales, Carlos Javier de, Religión, política y tolerancia en la Europa Moderna (Madrid: Polifemo, 2009).

Martínez Millán, José, “Introducción” y "La reconfiguración de la Monarquía Católica (siglos XVII al XVIII), en ¿ Decadencia o Reconfiguración? Las Monarquias de España y Portugal en el cambio de siglo (1640-1724), dirs. José Martínez Millán, Félix Labrador Arroyo y Filipa M. Valido-Viegas de Paula Soares, (Madrid: Polifemo, 2017), 1-6; 7-62.

Martínez Millán, José, “Introducción”, en La Corte de Felipe IV (1621-1665). Reconfiguración de la Monarquía católica, Tomo I, Vol. 1, dirs. José Martínez Millán y José Eloy Hortal Muñoz (Madrid: Polifemo, 2015), 3-56.

Martínez Millán, José, El mito de Faetón o la imagen de la decadencia de la Monarquía Católica (Granada: Ediciones de la Universidad de Granada, 2011).

Michelet, Jules, El pueblo (México: Fondo de Cultura Económica, 2005).

Prodi, Paolo, El soberano pontífice. Un cuerpo y dos almas: la monarquia papal en la primera Edad Moderna (Madrid: Akal, 2011).

Quental, Antero de, Causas de la decadencia de lospueblos peninsulares. Traducción y prólogo de César Rina Simón (Madrid: Marcial Pons, 2017).

Quental, Antero de, Prosas sócio-políticas (Lisboa: Imprensa Nacional Casa da moeda, 1982).

Reale, Miguel, Traços fundamentais da cultura portuguesa (Lisboa: Planeta, 2017).

Ribeiro dos Santos, Leonel, Antero de Quental. Uma visão moral do mundo (Lisboa: Imprensa Nacional Casa da Moeda, 2002).

Rina, César, "Decadencia, regeneración y revolución. La historia peninsular según Antero de Quental", en A. Quental, Causas de la decadencia de los pueblos peninsulares. Traducción y prólogo de César Rina Simón (Madrid: Marcial Pons, 2017), 11-44.

Schaub, Jean-Frédéric, Le Portugal au temps du Comte-Duc d'Olivares (1621-1640). Le conflit de jurisdictions comme exercice de la politique, (Madrid: Casa de Velázquez, 2011).

Serrão, Joel, "Génese e estrutura do pensamiento sócio-político de Antero de Quental", Prólogo a Quental, Antero de, Prosas sócio-políticas (Lisboa: Imprensa Nacional Casa da moeda, 1982), 78-86. 
Versteegen, Gijs, Corte y Estado en la historiografía liberal. Un cambio de paradigma (Madrid: Polifemo, 2015).

Wheeler, Douglas, Republican Portugal. A Political History 1910-1926 (Wisconsin: University of Wisconsin Press, 1978).

Wolf, Eric, Europa y la gente sin historia (Buenos Aires: Fondo de Cultura Económica, 2005

Recibido: 8 de agosto de 2019 Aprobado: 13 de octubre de 2019 